\title{
Comparative study of Succinylcholine, Rocuronium and Vecuronium for intubation and hemodynamic changes during general anaesthesia
}

\author{
Dr. Shaik Mira Shareef ${ }^{1}$, Associate Professor, \\ Dr. G. Sudharani ${ }^{2}$, Assistant Professor, \\ Guntur Medical College, Government General Hospital,Guntur.
}

\begin{abstract}
Introduction: Oro-tracheal intubation is an established technique to secure a patent airway, in patients considered to be at risk for aspiration of gastric contents. The goal of rapid sequence induction is to secure the patients airway smoothly and quickly minimizing the chances of regurgitation and aspiration of gastric contents. Its use is indicated in the presence of full stomach in emergency situations and other situations where there is an increased risk of aspiration.

Aim: Comparative study of Succinylcholine, Rocuronium and Vecuronium for intubation and hemodynamic changes during general anaesthesia

Results: It was concluded from this study Rocuronium produces intubating conditions which are satisfactory in comparison to Succinylcholine. Rocuronium is haemodynamically stable except for slight tachycardia and has no adverse effects. It may be a suitable alternative to Succinyl choline for intubation especially in patients who are at the risk of adverse effect of Succinyl choline. Vecuronium is also haemodynamically stable with no adverse effects. But for its delayed onset of action, it cannot be a better alternative to Succinylcholine when compared to Rocuronium.
\end{abstract}

\section{Introduction}

Maintenance of a patent airway is a basic and essential component of general anaesthesia.Muscle relaxants are useful in providing adequate relaxation and enable laryngoscopy and intubation.Rapid sequence induction and oro-tracheal intubation is an established technique to secure a patent airway, in patients considered to be at risk for aspiration of gastric contents. The goal of rapid sequence induction is to secure the patients airway smoothly and quickly minimizing the chances of regurgitation and aspiration of gastric contents. Its use is indicated in the presence of full stomach in emergency situations and other situations where there is an increased risk of aspiration.

Traditionally Succinylcholine has been the neuromuscular blocking drug of choice in rapid sequence induction and intubation technique. Yet its use is associated with a number of undesirable side effects ${ }^{1}$ like fasciculations, myalgia, hyperkalemia, bradyarrhythmias, raised intraocular, intracranial and intragastric pressures, anaphylaxis, malignant hyperthermia and masseter spasm. Hence it is not suitable in situations when patients have neuromuscular disorders, burns, head injury, intracranial bleeding, open eye injury, spinal cord injury and cerebrovascular accidents. The potential problems associated with Succinylcholine have prompted the search for alternative methods, the use of non depolarizing muscle relaxants (NDMR) for rapid sequence intubation.
Aims And Objectives changesduring general anaesthesia.
Objectives :
- To search for a suitable alternative for succinylcholine for intubation.
- To study and compare the intubating conditions.
- To study and compare the haemodynamic changes

Aim : Comparative study of Succinylcholine, Rocuronium and Vecuronium for intubation and hemodynamic

\section{Materials \& Methods}

A clinical study comparing rocuronium bromide $0.6 \mathrm{mg} \mathrm{kg}^{-1}$ and vecuronium $0.1 \mathrm{mg} / \mathrm{kg}$ with succinylcholine chloride $1.5 \mathrm{mg} \mathrm{kg}^{-1}$ for use during intubation of anaesthesia in adult patients was undertaken at Government General Hospital, Guntur attached to Guntur Medical College, during the period from 05-11-2015 to 30-01-2016 after obtaining ethical committee clearance. 
The study population consisted of 75 adult patients of ASA grade I and II belonging to both sexes in the age group of 18 to 60 years who were posted for various elective surgeries at Government General Hospital,Guntur. Informed consent was obtained from the patients before taking up for surgery.

Exclusion criteria consisted of patients with hypertension, diabetes, bronchial asthma, ischaemic heart disease or anticipated difficult airway.The study population was randomly divided into three groups with 25 patients in each group.

Group I consisting of 25 patients were to receive succinylcholine chloride $1.5 \mathrm{mg} \mathrm{kg} \mathrm{g}^{-1}$ body weight and intubation attempted at 60 seconds.

Group II consisting of 25 patients were to receive rocuronium bromide $0.6 \mathrm{mg} \mathrm{kg}^{-1}$ body weight and intubation attempted at 60 seconds.

Group III consisting of 25 patients were to receive vecuronium bromide $0.1 \mathrm{mg} \mathrm{kg}^{-1}$ body weight and intubation attempted at 60 seconds.

A thorough preanaesthetic evaluation was done a day before surgery and all the necessary investigations were done to rule out any systemic disease. Patients were maintained nil per oral for duration of 10 hours prior to surgery.The baseline heart rate, oxygen saturation and electrocardiogram, systolic, diastolic, mean arterial blood pressure and capnography were recorded using multichannel monitor. All patients were pre medicated and preoxygenated with $100 \%$ oxygen via a face mask for 3 minutes. They were induced with injection thiopentone sodium $5 \mathrm{mg} \mathrm{kg}^{-1}$ body weight intranvenously.In all the three groups of patients, oral endotracheal intubation was attempted at 60 seconds following the administration of muscle relaxant and intubating conditions were graded using the score adopted by Cooper et al. (1993).

Excellent = Jaw relaxed, vocal cords apart and immobile, no diaphragmatic movements.

Good= Jaw relaxed, vocal cords apart and immobile, some diaphragmatic movements.

Poor= Jaw relaxed, vocal cords moving and bucking.

Inadequate $=$ Jaw not relaxed, vocal cords closed

All the patients were intubated with well lubricated appropriate sized oral endotracheal tubes (cuffed), bilateral air entry was checked and the tube was firmly secured. Maintainance of anaesthesia was done with $33 \%$ oxygen and $66 \%$ nitrous oxide and IPPV.Monitoring of vital parameters like heart rate, oxygen saturation, systolic, diastolic and mean arterial blood pressures, electrocardiogram, capnograph were recorded 1, 5,10 and 15 minutes following intubation.At the end of surgery all the patients were reversed with injection neostigmine $0.05 \mathrm{mg} \mathrm{kg}^{-1}$ body weight and injection atropine $0.02 \mathrm{mg} \mathrm{kg}^{-1}$ body weight. Other side effects like histamine releasing property associated with administration of rocuronium bromide and succinylcholine chloride were also noted.The haemodynamic parameters in the present study were recorded in a prepared proforma,the data was grouped to various tabulations, analysed and compared statistically using $\mathrm{p}$ value obtained from student $\mathrm{t}$ test,taking the help of a computer.

Statistical Analysis:

At the end of study the results were group and analysed for statistical significance by using Chi-square test, $t$ test and ANOVA test. Categorical values like age, sex, and intubation score were analysed with ChiSquare test. Comparison between three groups with respect to continuous variables such as age, weight, duration of Laryngoscope ewere compared with t test and ANOVA test.

\section{Results \& Discussion}

The study population consisted of 75 patients divided into three groups.

Group I $(\mathrm{n}=25)$ was intubated with Succinylcholine chloride $1.5 \mathrm{mg} \mathrm{kg}^{-1}$ body weight. Group II $(\mathrm{n}=25)$ was intubated with rocuronium bromide $0.6 \mathrm{mg} \mathrm{kg}^{-1}$ body weight. Group III $(\mathrm{n}=25)$ was intubated with vecuronium bromide $0.1 \mathrm{mg} \mathrm{kg}^{-1}$ body weight.

TABLE

Age distribution : The age distribution of all the three groups is as shown below:

\begin{tabular}{|l|l|l|l|l|l|l|}
\hline \multirow{2}{*}{$\begin{array}{l}\text { Age } \\
\text { years) }\end{array}$} & \multicolumn{2}{|l|}{ Study Groups } & Rocuronium & \multicolumn{2}{l|}{ Vecuronium } \\
\cline { 2 - 7 } & Succinylcholine & $36.00 \%$ & 9 & $35.30 \%$ & 11 & $42.42 \%$ \\
\hline $\mathbf{1 0 - 2 9}$ & 10 & $59.08 \%$ & 13 & $52.83 \%$ & 11 & $45.16 \%$ \\
\hline $\mathbf{3 0 - 4 9}$ & 14 & $4.92 \%$ & 3 & $11.87 \%$ & 3 & $12.42 \%$ \\
\hline $\mathbf{5 0 - 6 9}$ & 1 & $100.00 \%$ & 25 & $100.00 \%$ & 25 & $100.00 \%$ \\
\hline
\end{tabular}

Chi-Square Value $=0.561$ at $\mathrm{df}=4$ and $\mathrm{P}>0.05$ Not Significant

TABLE

Sex distribution :

\begin{tabular}{|c|c|c|c|}
\hline \multirow[t]{2}{*}{ Sex } & \multicolumn{3}{|l|}{ Study Groups } \\
\hline & Succinylcholine & Rocuronium & Vecuronium \\
\hline Male & $13(29.54 \%)$ & $17(38.64 \%)$ & $14(31.82 \%)$ \\
\hline
\end{tabular}


Comparative study of Succinylcholine, Rocuronium and Vecuronium for intubation and

\begin{tabular}{|l|l|l|l|}
\hline Female & $12(38.71 \%)$ & $8(25.81 \%)$ & $11(35.48 \%)$ \\
\hline Total & 25 & 25 & 25 \\
\hline Chi-square Value $=0.544$ at df $=2$ and $\mathrm{P}<0.05$ Not Significant \\
\hline
\end{tabular}

TABLE

Weight Distribution :

\begin{tabular}{|l|l|l|l|l|l|l|}
\hline \multirow{3}{*}{ Wt (Kgs) } & \multicolumn{2}{l}{ Study Groups } & \multicolumn{2}{l|}{ Rocuronium } & \multicolumn{2}{l|}{ Vecuronium } \\
\cline { 2 - 7 } & Succinylcholine & No. & \% & No. & $\%$ \\
\cline { 2 - 7 } & No. & $\%$ & 9 & $34.74 \%$ & 10 & $43.08 \%$ \\
\hline $\mathbf{3 0 - 4 9}$ & 9 & $35.62 \%$ & 12 & $46.53 \%$ & 14 & $49.85 \%$ \\
\hline $\mathbf{5 0 - 6 9}$ & 14 & $55.56 \%$ & 4 & $18.74 \%$ & 1 & $7.08 \%$ \\
\hline $\mathbf{7 0 - 8 9}$ & 2 & $8.83 \%$ & 25 & $100.00 \%$ & 25 & $100.00 \%$ \\
\hline Total & 25 & $100.00 \%$ & $\mathbf{0 . 9 5 8}$ at df $=\mathbf{4}$ and P $\mathbf{>} 0.05$ Not Significant \\
\hline Chi-Square Value $=\mathbf{0}$
\end{tabular}

TABLE

\begin{tabular}{|l|l|l|l|l|l|l|}
\hline $\begin{array}{l}\text { Demographic Profile } \\
\text { of } \begin{array}{l}\text { Succinylcholine } \\
\text { groups }\end{array}\end{array}$ & Rocuronium & VEcuronium & $\begin{array}{l}\text { ANOVA } \\
\text { F-Statastic }\end{array}$ & P Value & Inference \\
\hline Sample Size (n) & 25 & 25 & 25 & & \\
\hline $\begin{array}{l}\text { Age(Yrs) } \\
\text { Mean +/-SD) }\end{array}$ & $30.36+/-10.11$ & $33.6+/-13.61$ & $33 \pm 12.17$ & 0.51 & 0.602 & NS \\
\hline $\begin{array}{l}\text { Weight(Kgs) } \\
\text { (Mean +/-SD) }\end{array}$ & $50.68+/-10.86$ & $53.8+/-11.75$ & $52.96 \pm 10.61$ & 0.55 & 0.582 & NS \\
\hline Male : Female & $13: 12$ & $14: 11$ & $14: 11$ & & & \\
\hline
\end{tabular}

TABLE

Duration of Laryngoscopy

\begin{tabular}{|l|l|l|l|}
\hline \multirow{2}{*}{$\begin{array}{l}\text { Duration of Laryngoscopy } \\
\text { Seconds) }\end{array}$} & No., of Patients & Vecuronium \\
\cline { 2 - 4 } & Suxamethonium & Rocuronium & 0 \\
\hline $30-49$ & 25 & 12 & 4 \\
\hline $50-69$ & 0 & 11 & 14 \\
\hline $70-89$ & 0 & 2 & 6 \\
\hline $90-109$ & 0 & 0 & 1 \\
\hline $110-129$ & 0 & 0 & 25 \\
\hline Grand Total & 25 & 25 & $82.36+/-13.16$ \\
\hline Mean +/- SD & $39.4+/-4.56$ & $53.00 \pm 9.16$ \\
\hline $\begin{array}{l}\text { ANOVA Single Factor } \\
\text { F - Statistic }\end{array}$ & 130.1 & & \\
\hline P Value & 0.001 & \\
\hline Inference & Highly Significant \\
\hline
\end{tabular}

The mean onset of time of intubation for succinylcholine is $39.4 \pm 4.56$, for rocuronium $53.00 \pm 9.16$, and for vecuronium $82.36 \pm 13.16$. so onset of vecuronium os longer than succinylcholine and rocuronium which is highly significant with $\mathrm{p}$ value 0.001 .

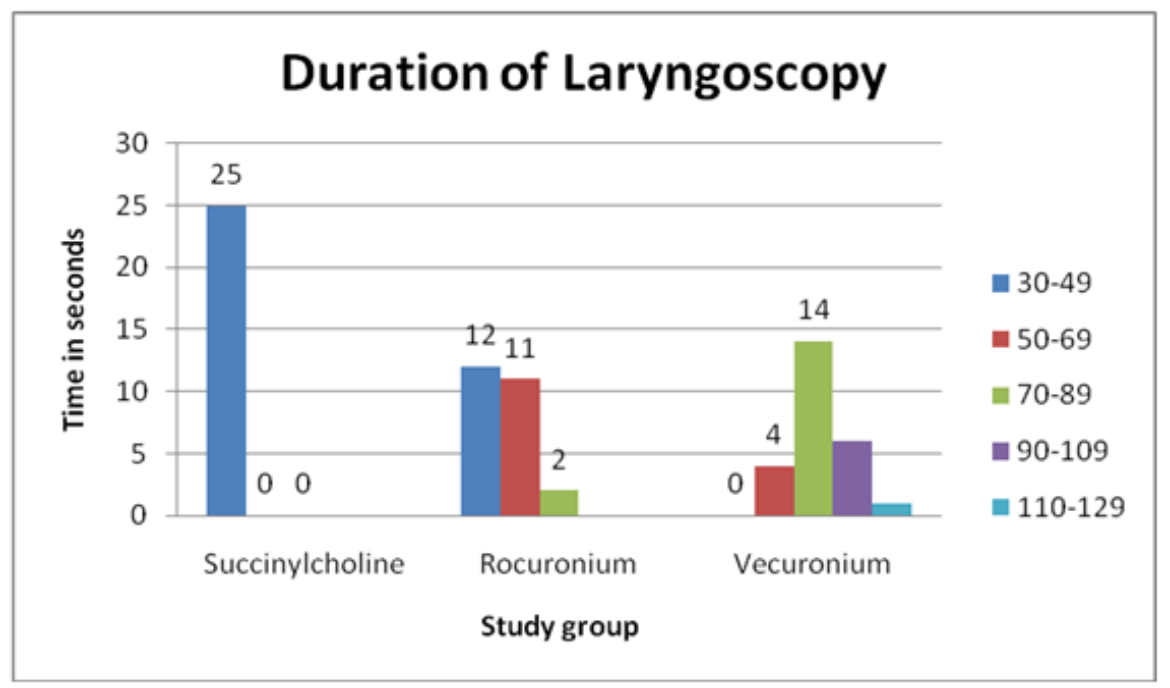


TABLE

Intubation Score : The following table shows the intubation score in three groups ( based upon Cooper et al, 1993).

\begin{tabular}{|c|c|c|c|c|c|c|}
\hline \multirow[t]{3}{*}{ Intubation Score } & \multicolumn{6}{|c|}{ Study Groups } \\
\hline & \multicolumn{2}{|c|}{ Succinylcholine } & \multicolumn{2}{|c|}{ Rocuronium } & \multicolumn{2}{|c|}{ Vecuronium } \\
\hline & No. & $20.00 \%$ & No. & $\%$ & No. & $\%$ \\
\hline Excellent & 22 & $40.00 \%$ & 10 & $40.00 \%$ & 5 & $20.00 \%$ \\
\hline Good & 3 & $40.00 \%$ & 12 & $48.00 \%$ & 10 & $40.00 \%$ \\
\hline Poor & 0 & $100.00 \%$ & 3 & $12.00 \%$ & 10 & $40.00 \%$ \\
\hline Total & 25 & $100.00 \%$ & 25 & $100.00 \%$ & 25 & $100.00 \%$ \\
\hline
\end{tabular}

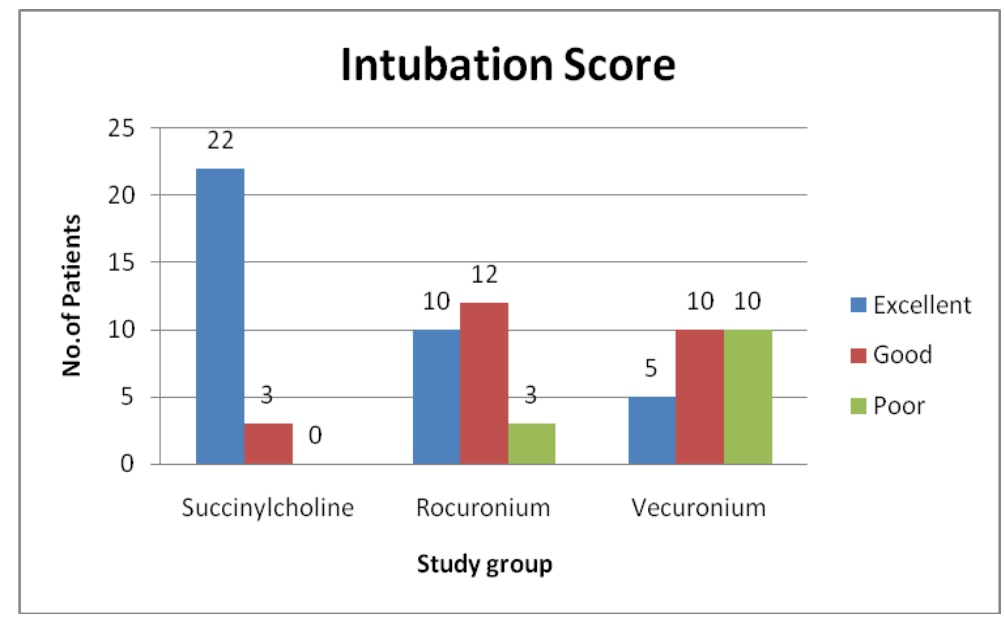

As it is in the table No.5 in group I ( $\mathrm{n}=25)$ patients who received Succinylcholine $1.5 \mathrm{mg} / \mathrm{kg}$ body weight, 20 patients has excellent intubating conditions with jaw relaxed, vocal cords apart and immobile and no diaphragmatic movements.and 3 patients has Good intubation score with jaw relaxed, vocal cards apart, and immobile, some diaphragmatic movements. So, in this group total 25 patients $(100 \%)$ had either excellent or good intubatory conditions.

In group II $(\mathrm{n}=25)$ who received Rocuronium Bromide $0.6 \mathrm{mg} / \mathrm{kg}$ body weight, 10 patients has excellent intubating conditions with jaw relaxed, vocal cords apart and immobile and no diaphragmatic movements and 12 members has Good intubation score with jaw relaxed, vocal cards apart, and immobile, some diaphragmatic movements. 3 patients has poor intubating condition with vocal cord moving and bucking after intubation. Even in this patient who had poor intubating condition, intubation was possible at $60 \mathrm{sec}$. as the jaw was relaxed. All together in group II 88\% patients , i.e., 22 pateints out of 25 had excellent, good intubating conditions at $60 \mathrm{sec}$.

In group III ( $\mathrm{n}=25)$ who received Vecuronium bromide $0.1 \mathrm{mg} / \mathrm{kg}$ body weight 5 patients had excellent intubating conditions, in 10 patients had good intubating conditions and 10 patients had poor intubating status, even in these patients who had intubation is possible after jaw was completely relaxed without any complications. All together in group III $60 \%$ patients, i.e., 15 patients out of 25 had excellent, good intubating conditions.

TABLE

Mean Heart Rate : The following table shows the mean heart rate values as follws:

\begin{tabular}{|l|l|l|l|l|l|l|}
\hline Heart Rate at & $\begin{array}{l}\text { Succinylcholine } \\
(\mathbf{n = 2 5}) \\
\text { Mean +/- SD }\end{array}$ & $\begin{array}{l}\text { Rocuronium } \\
(\mathbf{n = 2 5}) \\
\text { Mean +/- SD }\end{array}$ & $\begin{array}{l}\text { Vecuronium } \\
(\mathbf{n = 2 5}) \\
\text { Mean +/- SD }\end{array}$ & $\begin{array}{l}\text { ANOVA } \\
\text { Single } \\
\text { Factor } \\
(\mathbf{F} \text { - statistic })\end{array}$ & $\begin{array}{l}\mathbf{P} \text { - } \\
\text { Value }\end{array}$ & Inference \\
\hline Base Line & $90.72+/-11.06$ & $93.48+/-9.67$ & $83.48+/-11.26$ & 5.83 & 0.004 & Significant \\
\hline 1M after induction & $96.04+/-11.93$ & $101.84+/-13.43$ & $90.88+/-12.53$ & 4.70 & 0.012 & Significant \\
\hline 1M after intubation & $101.56+/-14.53$ & $104.12+/-13.34$ & $93.24+/-13.98$ & 4.15 & 0.020 & Significant \\
\hline 5M after intubation & $97.6+/-15.25$ & $104.56+/-16.69$ & $96.24+/-12.46$ & 2.24 & 0.114 & NS \\
\hline 10M after intubation & $97.2+/-17.07$ & $101.36+/-21.15$ & $95.04+/-21.38$ & 0.65 & 0.527 & NS \\
\hline
\end{tabular}

There is no significant difference in heart rate among three groups and even some mild tachycardia is noted for Rocuronium i.e., only due to hemodynamic response to intubation and laryngoscopy. 
TABLE

Mean Arterial Pressure :

\begin{tabular}{|c|c|c|c|c|c|c|}
\hline MAP at & $\begin{array}{l}\text { Succinylcholine } \\
(n=25) \\
\text { Mean +/- SD }\end{array}$ & $\begin{array}{l}\text { Rocuronium } \\
(n=25) \\
\text { Mean +/- SD }\end{array}$ & $\begin{array}{l}\text { Vecuronium } \\
(n=25) \\
\text { Mean +/- SD }\end{array}$ & $\begin{array}{lr}\text { ANOVA } & \text { Single } \\
\text { Factor(F } & \text { - } \\
\text { statistic) } & \end{array}$ & $\begin{array}{l}\mathbf{P}- \\
\text { Value }\end{array}$ & $\begin{array}{l}\text { Inferen } \\
\text { ce }\end{array}$ \\
\hline Base Line & $89.12+/-9.27$ & $87.64+/-11.97$ & $90.68+/-8.33$ & 0.58 & 0.563 & NS \\
\hline $\begin{array}{ll}1 \mathrm{M} & \text { after } \\
\text { induction } & \end{array}$ & $99.24+/-12.22$ & $98.64+/-14.60$ & $98.04+/-11.05$ & 0.06 & 0.946 & NS \\
\hline $\begin{array}{ll}1 \mathrm{M} & \text { after } \\
\text { intubation }\end{array}$ & $106.72+/-12.81$ & $103+/-11.66$ & $101.24+/-16.25$ & 1.04 & 0.359 & NS \\
\hline $\begin{array}{ll}5 \mathrm{M} & \text { after } \\
\text { intubation } & \end{array}$ & $101.48+/-17.91$ & $98.56+/-11.86$ & $104.36+/-12.52$ & 1.02 & 0.366 & NS \\
\hline $\begin{array}{ll}10 \mathrm{M} & \text { after } \\
\text { intubation } & \end{array}$ & $93.72+/-12.23$ & $96.64+/-13.64$ & $100.48+/-12.59$ & 1.74 & 0.182 & $\mathbf{N S}$ \\
\hline
\end{tabular}

All the pateints are haemodynamically stable, no significant difference in mean arterial pressure in all 3 groups.

Table

Comparison of the intubating conditions with succinylcholine chloride at 60 seconds by various authors and present study

\begin{tabular}{|c|c|c|c|c|}
\hline $\begin{array}{r}\text { Authors } \\
\end{array}$ & Excellent & Good & Poor & Inadequate \\
\hline 1. Cooper etal. $1992(n=20)^{38}$ & $19(95 \%)$ & $1(5 \%)$ & - & - \\
\hline 2. Friedrich K. Puhringer et al. $1992(n=10)$ & $8(80 \%)$ & $1(10 \%)$ & $1(10 \%)$ & \\
\hline 3. Toni Magorian et al. $1993(\mathrm{n}=-10)$ & $8(80 \%)$ & $2(20 \%)$ & - & - \\
\hline 4. Naguib M. et al. $1997(n=10)$ & $9(90 \%)$ & $1(10 \%)$ & - & - \\
\hline 5. K.C. McCourt et al. $(n=127)$ & $101(80 \%)$ & $22(17 \%)$ & $4(3 \%)$ & - \\
\hline 6.Dr.Misra MN et al.2005, $(n=30)$ & $27(90 \%)$ & $2(6.7 \%)$ & $1(3.3 \%)$ & \\
\hline 7. Present study $(n=25)$ & $22(88 \%)$ & $3(12 \%)$ & - & - \\
\hline
\end{tabular}

It is noted that with succinylcholine chloride Cooper et al. and Naguib et al. have obtained excellent intubating conditions in $95 \%$ and $90 \%$ of cases respectively. Only three authors Friedrich K., Puhringer et al., Misra et al and K.C. McCourt et al. have noted poor intubating conditions in 10\% and 3\% respectively. Most of other authors have noted good to excellent intubating conditions in $100 \%$ of cases. In the present study also succinylcholine chloride $1.5 \mathrm{mg} \mathrm{kg}^{-1}$ body weight produced excellent intubating conditions in $100 \%$ of cases which is comparable with that of Cooper et al. (1992) and Naguib etal. (1997) and Dr.Misra MN et al (2005).

Table

Comparison of Intubating conditions with rocuronium bromide $0.6 \mathrm{mg} \mathrm{kg} \mathrm{kg}^{-1}$ body weight at 60 seconds by various authors and present study.

\begin{tabular}{|l|l|l|l|l|}
\hline \multicolumn{1}{|c|}{ Authors } & Excellent & Good & Poor & Inadequate \\
\hline 1. Cooper etal. 1992 $(\mathrm{n}=20)^{38}$ & $13(65 \%)$ & $6(30 \%)$ & $1(5 \%)$ & - \\
\hline 2. Friedrich K. Puhringer et al. 1992 $(\mathrm{n}=20)$ & $17(85 \%)$ & $3(15 \%)$ & & \\
\hline 3. Naguib M. et al. 1997 $(\mathrm{n}=10)$ & $7(70 \%)$ & $3(30 \%)$ & - & - \\
\hline 4. K.C. McCourt et al. 1997 $(\mathrm{n}=57)$ & $16(28 \%)$ & $27(47 \%)$ & $14(25 \%)$ & - \\
\hline 5. Aparna Shukla et al. 2004 $(\mathrm{n}=20)$ & $10(50 \%)$ & $6(30 \%)$ & $4(20 \%)$ & - \\
\hline 67.Misra M.N. et al 2005( $\mathrm{n}=30)$ & $21(70 \%)$ & $7(20 \%)$ & $2(10 \%)$ & \\
\hline 7. Present study $(\mathbf{n}=\mathbf{2 5})$ & $\begin{array}{l}10 \\
(40 \%)\end{array}$ & $\begin{array}{l}12 \\
(48 \%)\end{array}$ & $3(12 \%)$ & \\
\hline
\end{tabular}

Thus it is noted from the above table that the incidence of excellent intubating conditions with rocuronium bromide $0.6 \mathrm{mg} \mathrm{kg}^{-1}$ body weight ranged from $28 \%$ in the study of K.C. McCourt et al. (1997) to $85 \%$ in the study of Friedrich K. Puhringer et al. (1992). The incidence of good intubating conditions ranged from $15 \%$ in the study of Friedrich K. Puhringer et al. (1992) to 47\% in the study of K.C. McCourt et al. (1997). Three authors have noted poor intubating conditions with 5\% in the study of Cooper et al. (1992), 20\% in the study of Aparna Shukla et al. (2004) and 25\% in the study of K.C. McCourt etal. (1997).

In the present study 10 patients $(40 \%)$ had excellent intubating conditions with rocuronium bromide $0.6 \mathrm{mg} \mathrm{kg}^{-1}$ body weight at 60 seconds which concurs with studies of Aparna Shukla et al. (2004). 12 patients $(48 \%)$ out of 30 had good intubating conditions which concurs with studies of K.C. McCourt et al. (1997). Three patients $(12 \%)$ in the present study had poor intubating condition with jaw relaxed, vocal cords moving and bucking after intubation. However even in this patient intubation was accomplished at 60 seconds. This concurs with study of Aparna Shukla etal.(2004). 
Table

Comparison of intubating conditions of vecuronium $0.1 \mathrm{mg} / \mathrm{kg}$ bodyweight by various authors and present study.

\begin{tabular}{|l|l|l|l|l|}
\hline \multicolumn{1}{|c|}{ Authors } & Excellent & Good & Poor & Inadequate \\
\hline 1. Kanthy et al. 1989 $(\mathrm{n}=30)$ & $24(80 \%)$ & $5(16.71 \%)$ & $1(3.31 \%)$ & - \\
\hline 2.Tony Magorian et al 1993 & $6(60 \%)$ & $3(30 \%)$ & $1(10 \%)$ & \\
\hline 3.Dr.Mishra MN et al (2005) & $4(13 \% 0$ & $17(60 \%)$ & $9(27 \%)$ & - \\
\hline 4.V.Abraham, ArtiRaj Kumar et al 2008(ITA) & $12(20 \%)$ & $47(78 \%)$ & $1(1.7 \%)$ & - \\
\hline 5.Veenachathran et al 2010act & $12(48 \%)$ & $12(48 \%)$ & $1(4 \%)$ & - \\
\hline 6.Present study $(\mathbf{n}=\mathbf{2 5})$ & $5(20 \%)$ & $10(40 \%)$ & $7(28 \%)$ & \\
\hline
\end{tabular}

This is noted that Good to Excellent conditions was 73\%in Mishra et al ,90\% in Magorian et al , 96\% inVeenachatran et al .Only Misra et al had 27\% Poor intubating conditions. In present study Good to excellent is $60 \%$ and Poor condition is $28 \%$ so this study concerns with Dr.Misra et al.

\section{Haemodynamic Changes}

The cardiovascular changes following the administration of rocuronium bromide have been studied by Eamon P. McCoy et al. 1993 and Mark E. Hudson et al. 1998.Eamon P. McCoy et al. 1993 have demonstrated changes in heart rate $(+7 \%)$, mean arterial pressure $(-5 \%)$, systemic vascular resistance $(-12 \%)$, that were insignificant. They concluded that rocuronium bromide in doses of $0.6 \mathrm{mg} \mathrm{kg}^{-1}$ is associated with changes of only small magnitudes in haemodynamic variables.Mark E. Hudson et al. 1998 measured the haemodynamic effects of rocuronium bromide in adults undergoing cardiac surgery with cardiopulmonary bypass. They found the haemodynamic profile for a dose of $0.6 \mathrm{mg} \mathrm{kg}^{-1}$ bolus of rocuronium bromide to be acceptable for patients with coronary artery disease. There was no change in myocardial oxygen demand and supply. Although CVP and PAP decreased significantly, rocuronium bromide had no effect on pulmonary capillary wedge pressure, systemic vascular resistance, mean arterial pressure and cardiac index. Thus rocuronium bromide has been demonstrated to be haemodynamically a stable drug.

In our study, there was no change in haemodynamic variables following the administration of succinyl cholene, rocuronium and vecuronium. There is only a rise of pulse rate with rocuronium 1 min.after intubation. This was a haemodynamic response to Laryngoscopy and endotracheal intubation which subsided to near pre induction values at $5 \mathrm{~min}$. after intubation. It was concluded from this study Rocuronium produces intubating conditions which are satisfactory in comparison to Succinylcholine. Rocuronium is haemodynamically stable except for slight tachycardia and has no adverse effects. It may be a suitable alternative to Succinyl choline for intubation especially in patients who are at the risk of adverse effect of Succinyl choline. Vecuronium is also haemodynamically stable with no adverse effects. But for its delayed onset of action, it cannot be a better alternative to Succinylcholine when compared to Rocuronium.

\section{Conclusions}

1. Succinylcholine chloride $1.5 \mathrm{mg} \mathrm{kg}^{-1}$ body weight produces excellent intubating conditions in all the patients at 60 seconds

2. Rocuronium bromide $0.6 \mathrm{mg} \mathrm{kg}^{-1}$ body weight produces good to excellent intubating conditions in $88 \%$ of patients at 60 seconds

3. VEcuronium $0.1 \mathrm{mg} / \mathrm{kg}$ body weight produces Good to Excellent conditions in $60 \%$ of the patients only at $60 \mathrm{sec}$.

4. Rocuronium bromide is safe alternative to succinylcholene for intubation when compared to vecuronium.

5. There is no significant changing hemodynamic parameters like heart rate systolic blood pressure, diastolic blood pressure and mean arterial blood pressure in any of these groups.

\section{Bibliography}

[1]. Naguib M, Lien Cynthia A. Pharmacology of muscle relaxants and their antagonists. Chapter 13. In Miller's anaesthesia. $6^{\text {th }}$ edn., edt., Miller R.D. Churchill Livingstone, Philadelphia, 2005; pp: 481-547.

[2]. Magorian T, Flannery KB, Miller RD: Comparison of rocuronium, succinylcholine, and vecuronium for rapid sequence induction of anesthesia in adult patients. Anesthesiology. 1993; 79: 913-918.

[3]. Copenhagen consenses conference guidelines - 1994 -

[4]. Aparna Shukla, Dubey KP, Sharma MSN: Comparative evaluation of haemodynamic effects and intubating conditions after the administration of ORG 9426 and succinylcholine, Indian Journal of Anaesthesia, 2004; 48(6): 476-479

[5]. Dr Misra MN, et al (2005) A comparative study of Rocuronium, Vcuronium and succinyl choline for rapid sequence induction of anesthesia. Indian J Anaesthes.2005;49(6):469-473.

[6]. Veena Chatrath et al Comparison of intubating conditions of Rocuronium bromide and vecuronium bromide with succinylcholine using "Time principle" J Anesthesiol Clin Pharmacol 2010 Oct-Dec;26(4):493-497. 